\title{
Corpus
}

\section{The Omission of Preverbal Subject Clitics in Friulian: Methodology and Constraint-Based Analysis}

\section{Sascha Gaglia}

\section{CpenEdition}

Journals

Édition électronique

URL : http://journals.openedition.org/corpus/1905

DOI : 10.4000/corpus.1905

ISSN : 1765-3126

Éditeur

Bases; corpus et langage - UMR 6039

Édition imprimée

Date de publication : 1 novembre 2010

Pagination : 191-220

ISSN : 1638-9808

Référence électronique

Sascha Gaglia, «The Omission of Preverbal Subject Clitics in Friulian: Methodology and ConstraintBased Analysis », Corpus [En ligne], 9 | 2010, mis en ligne le 07 juillet 2011, consulté le 07 septembre 2020. URL : http://journals.openedition.org/corpus/1905; DOI : https://doi.org/10.4000/corpus.1905 


\title{
The Omission of Preverbal Subject Clitics in Friulian: Methodology and Constraint-Based Analysis ${ }^{1}$
}

\author{
Sascha GAGLIA \\ Universität Göttingen
}

\section{Introduction}

Friulian varieties exhibit a double series of subject pronouns (free pronouns vs. clitics), which is also the case in some other Romance dialects, e.g. Northern Italian dialects (cf. Marchetti 1952, Gregor 1975, Renzi \& Vanelli 1983, Frau 1984, Poletto 2000, Heap 2000, Manzini \& Savoia 2005, Vicario 2005). The example in (1) displays the 1SG SCL $o$ in preverbal position and following the optional free subject pronoun jo (cf. Marchetti 1952: 222). ${ }^{2}$

$$
\begin{aligned}
& (\mathrm{Jo}) \boldsymbol{o} \quad \text { feveli } \\
& \text { PRO SCL.1SG speak-1SG PRES. IND. } \\
& \text { 'I speak'. }
\end{aligned}
$$

According to Friulian grammars, preverbal SCLs with the exception of 2SG may be omitted in the presence of the negation

1 The present study was partially financed by the collaborative research center SFB 471 ('Variation and change in the lexicon') at the University of Konstanz, and was supported by the German research council. Further, I would also like to thank Loredana Brovedani, Friederike von Criegern, Hans Goebl, Franziska Hack, Marc-Olivier Hinzelin, Georg Kaiser, Steven Kaye, Stefano Quaglia, Caroline Runte, Christoph Schwarze, Bettina Stadie, Federico Vicario and Michael Zimmermann.

2 All translations and glosses are my own. In the present paper, I use the following abbreviations: $\mathrm{ACC}=$ accusative, $\mathrm{COND}=$ conditional, $\mathrm{DAT}=$ dative, $\mathrm{F}=$ feminine, $\mathrm{FUT}=$ future, $\mathrm{IMPF}=$ imperfect, $\mathrm{IND}=$ indicative, $\mathrm{M}$ $=$ masculine, NEG $=$ negation, NID $=$ Northern Italian dialect, $\mathrm{SG}=$ singular, $\mathrm{OCL}=$ object clitic, $\mathrm{PL}=$ plural, $\mathrm{PRES}=$ present, $\mathrm{PRO}=$ free pronoun, $\mathrm{SCL}=$ subject clitic, $\mathrm{SUBJ}=$ subjunctive, $\mathrm{v}=$ vowel. $\mathrm{On} \mathrm{pp} .23$ to 24 , I use the indexed abbreviation Vn for verb forms.

Corpus $\mathrm{n}^{\circ} 9$ 《La syntaxe de corpus / Corpus Syntax » (2010), 191-220 
particle no (2a, 2b) and OCLs (and reflexives) (3a, 3b) (cf. Marchetti 1952, Gregor 1975, Haiman \& Benincà 1992, Heinemann 2003, Hack \& Gaglia 2009). ${ }^{3}$ In Friulian, SCLs are realized in postnegative position, but they precede OCLs and reflexive pronouns. ${ }^{4}$

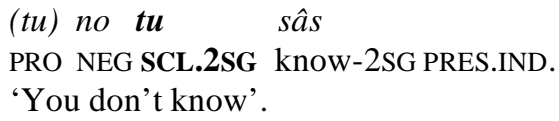

(3a) (tu) tu mi disis PRO SCL.2SG OCL.DAT tell-2SG PRES.IND. 'You tell me'.

(3b) il signor $\emptyset_{j} \quad$ veve sierât il grim the lord 3M.SG OCL.DAT had closed the womb 'The Lord had closed her womb'.

The conditions for preverbal SCL omission in the main varieties of Friulian (Carnic, Western Friulian, Central-Southern Friulian) have not been studied in detail up to now.

However, it is unclear if the co-occurrence of SCLs other than 2SG with the syntactic elements in question is ungrammatical or merely optional from an empirical perspective (see Hack \& Gaglia 2009: 174). A quantitative analysis, depending on the grammatical person, is provided within the present paper.

Empirically, my analysis is based on fieldwork data. Fieldwork was carried out with 52 native speakers of Friulian, and involved the elicitation of grammaticality judgements. The findings will be compared with claims made in Friulian grammars (Marchetti 1952, Gregor 1975), as well as with corpus data.

3 Examples (2a) and (3a) are taken from Marchetti (1952: 222 and 214 respectively). Example (2b) is taken from Bibie (1 Samuel 1,22) and (3b) from Bibie (1 Samuel 1, 5).

4 In the remainder of this article, the contexts for omission are also labeled as blocking environments. 
An important issue to be discussed in the present paper is the role of syncretism, since Friulian verb systems are highly syncretic. I will claim that SCLs in Friulian have the function of disambiguating syncretic verb forms. Against this backdrop, the omission of preverbal SCLs represents a paradox at first glance. I will show that a system of conflicting phonological and morphological constraints determines the use and deletion of preverbal SCLs in Friulian with respect to blocking environments. The framework I will use is that of Optimality Theory in its standard version (cf. McCarthy \& Prince 1993, Prince \& Smolensky 1993).

The remainder of this article is structured as follows: First, in section 2, I give a brief diatopic description of the facts regarding free and clitic subject pronouns. In section 3, I present the research method used and the empirical results as well as some remarks on methodology. A constraint-based analysis of the data gathered and presented follows in section 4. A summary of the paper and of its main results is supplied in section 5 .

\section{Linguistic description}

\subsection{Friulian}

Friulian is spoken in the administrative area of Friuli-VeneziaGiulia in the North-East of Italy and has the official status of a minority language. Its varieties are usually divided according to three areas: a) Central-Southern Friulian, which is the most widespread variety, exhibiting koiné status, b) Western Friulian, the most innovative variety, according to Vanelli (1997: 279) due to its close contact with the Veneto, and c) Carnic, which is spoken in the Alpine area (Francescato 1966a:91-125, Frau 1984: 14-16, Vanelli 1997: 279, Hack \& Gaglia 2009: 158). Friulian is often considered as a variety of Rhaeto-Romance, mainly owing to its phonology (Ascoli 1873, Gartner 1883, Haiman \& Benincà 1992, Liver 2010, Kaiser et al. 2001, Hack \& Gaglia 2009).

\subsection{The use of subject pronouns in Friulian}

As mentioned above, Friulian varieties display free subject pronouns (PRO) as well as SCLs (see Table 1). 
S. GAGLIA

Table 1. Free subject pronouns and subject clitics in the mainvarieties of Friulian

\begin{tabular}{|c|c|c|c|c|c|c|}
\hline & \multicolumn{2}{|c|}{$\begin{array}{l}\text { Ampezzo/ } \\
\text { Carnic } \\
\text { Friulian }\end{array}$} & \multicolumn{2}{|c|}{$\begin{array}{l}\text { Clauzetto/ } \\
\text { Western } \\
\text { Friulian }\end{array}$} & \multicolumn{2}{|c|}{$\begin{array}{c}\text { Udine/ } \\
\text { Centr.-South. } \\
\text { Friulian }\end{array}$} \\
\hline & PRO & SCL & PRO & SCL & PRO & SCL \\
\hline $1 \mathrm{SG}$ & jo & $i$ & jo & $o$ & jo & $o$ \\
\hline $2 \mathrm{SG}$ & tu & tu & $t u$ & tu & $t u$ & $t u$ \\
\hline 3M.SG & lui & al & lui & al & lui & al \\
\hline 3F.SG & $j \hat{e}$ & $a$ & ia & $a$ & $j \hat{e}$ & $e$ \\
\hline 1PL & $n \hat{o}$ & $i$ & $n \hat{o}$ & $o$ & $n \hat{o}$ & $o$ \\
\hline $2 \mathrm{PL}$ & vualtras & $i$ & vuatros & $o$ & vualtris & $o$ \\
\hline $3 \mathrm{PL}$ & lôr & $a$ & lûar & $a(j)^{1}$ & lôr & $a$ \\
\hline
\end{tabular}

The following paragraphs are concerned with the use and distribution of both series and with contexts of SCL omission, as they are presented in the existing literature in this field (cf. Marchetti 1952, Gregor 1975, Brovedani 1981, Haiman 1991, Haiman \& Benincà 1992, Vanelli 2005, Vicario 2005).

In Friulian, free subject pronouns are preposed or postponed to the verb in both declarative $(4 a, b)$ and interrogative sentences (4c,d) (cf. Marchetti 1952: 222).

(4a) jo o feveli

PRO SCL speak-1SG

'I speak'

(4b) o feveli jo

SCL speak-1SG PRO

'I speak'

(4c) jo fevelio?

PRO speak-1SG-SCL

'Do I speak?'

(4d) fevelio jo?

speak-1SG-SCL PRO

'Do I (probably) speak?' 
As in Italian, which is a null-subject (or pro-drop) language, Friulian free subject pronouns are only obligatory under certain circumstances, e.g. when used for contrast, emphasis, focus and anaphoric reference (cf. Cordin \& Calabrese 2001, among others). In the present paper, the role of free subject pronouns will only be considered with respect to syncretism in Italian.

As mentioned above, SCLs are realized in non-blocking environments (cf. Marchetti 1952: 222, Gregor 1975: 107, Haiman \& Benincà 1992: 179-181, Vanelli 2005: 23, Vicario 2005: 62). I call a non-blocking environment those contexts without negation, OCLs or reflexive pronouns. In blocking environments as well as in non-blocking environments, I expect differences in the single grammatical persons, according to Renzi \& Vanelli (1983) and Heap (2000, 2002) for Northern Italian dialects and for other Central Romance varieties.

Rizzi (1986) and Brandi \& Cordin (1989) show for Fiorentino and Trentino, that SCLS can be analyzed as agreement morphemes. According to their analyses, SCLs "are the spelling out of AGR under INFL" (cf. Rizzi 1986: 392-393, Brandi \& Cordin 1989: 115-116), instead of being attributed only to the verbal morphology. They are not syntactic arguments, because they co-occur with pronominal NPs (1) as well as with lexical NPs and with relative pronouns (5a,b; cf. Haiman 1991: 140-142).

(5a) in om al veve doifis

a man he had two son

'A man had two sons'.

(5b) dut che al e gno

all that he is mine

'all that which is mine'

Moreover, these SCLs are not referential (cf. Haiman 1991: 144), since they may paradoxically lack agreement with the subject (cf. Haiman 1991: 143 [Elwert 1943]). Hence, they cannot be interpreted as resumptive pronuns and must, therefore, cliticize to the verb.

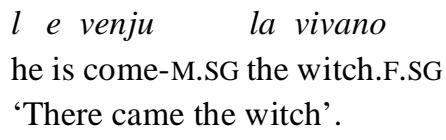


Additionally, SCL-paradigms may be defective, which is typical for affixes (cf. Rizzi 1986: 401, Brandi \& Cordin 1989: 113).

For Friulian, it has been claimed, that SCLs are always found adjacent to the verb ( $4 \mathrm{a}$ to $\mathrm{d}$ ). However, they occur preverbally in declarative sentences $(4 a, b)$ but as enclitics in interrogative sentences $(4 \mathrm{c}, \mathrm{d})$. In the present paper, I will show that SCLs in Friulian may also lose their adjacency to the verb, but only if the $3 \mathrm{PL}$ verb form is preceded by negation, as in (7):

$$
\begin{array}{lcl}
A & \text { no ciantin } \\
\text { scl.3pl neg } & \text { sing. } 3 \mathrm{pl}
\end{array}
$$

I will not adopt the view in Haiman (1991: 140), who treats SCLS in NIDs as bound agreement affixes, but rather accord to the syntactic analysis for SCLs proposed by Rizzi (1986: 393, 398-399), who treats SCLs and the negation particle as "members of the same clitic cluster, both being constituents of INFL". For Friulian, this is supported by the fact, that the negation particle and the SCL of 3PL may be reordered within a particular cluster, as already seen in (7). However, according to Rizzi (1986: 399), OCLs and the verb constitue a different cluster under VP, if OCLs cluster together without intervention of any other clitic, i.e. SCLs or the negation particle -which is the case for Friulian.

The paradigmatic distribution of SCLs in Friulian is complete, i.e. every person in the paradigm exhibits a SCL (cf. Vanelli 2005: 23, Vicario 2005: 62). ${ }^{5}$ For 3SG, a masculine and a feminine form exist (see Table 1). The SCLs of 1SG/1PL/2PL are syncretic: this holds true for all three of the main varieties of Friulian and is a widespread property of NIDs (cf. Renzi \& Vanelli 1983: 131). ${ }^{6}$ Moreover, the syncretic SCL is purely vocalic. This is also observable in Ladin and in other NIDs (cf. Renzi \& Vanelli 1983: 131, Haiman \& Benincà 1992: 179). The role of syncretism in SCL paradigms as well as in verb paradigms will be especially highlighted later on. The following paragraphs present the contexts for preverbal SCL omission.

5 For many Gallo-Romance dialects this is not the case. So-called 'split subject paradigms' are also observable there (cf. Heap 2000).

6 This is confirmed by the data in Manzini \& Savoia (2005: 72-82). 


\subsection{Contexts for SCL omission}

Most preverbal SCLs in Friulian are omitted if verbs are preceded by negation, or by OCLs or reflexive pronouns. ${ }^{7}$ By contrast, the $2 \mathrm{SG} \mathrm{SCL}$ is realized regularly in these contexts (see examples in (2) and (3)).

As mentioned before, it is unclear if the co-occurrence of SCLs other than $2 \mathrm{SG}$ with the syntactic elements in question is ungrammatical or merely optional from an empirical perspective (see Hack \& Gaglia 2009: 174). The same can be said with regard to SCL omission in non-blocking environments, which may also occur. Renzi \& Vanelli (1983) and Heap (2000, 2002) observe a realizational hierarchy of the SCLs in question with respect to Central Romance varieties. All three studies show a greater degree of realization of the SCLS of 2SG, 3SG and 3PL as compared to 1SG, 1PL and 2PL with some degree of divergence between the realization of SCLs in Renzi \& Vanelli (1983) and Heap (2000, 2002). Heap (2000) classifies the overall results into two blocks, $\mathrm{A}$ and $\mathrm{B} .{ }^{8}$ The divergence concernes the different hierarchical ranking of the grammatical persons within the two blocks beside $2 \mathrm{SG}$, which is always the most frequent one (see Table 2).

Table 2. Synopsis of the hierarchy of subject pronouns, following Heap (2000: 116)

\begin{tabular}{c|ccc}
\hline Rank & $\begin{array}{c}\text { Renzi \& Vanelli } \\
(1983)\end{array}$ & $\begin{array}{c}\text { Heap } \\
(2000)\end{array}$ & Block \\
\hline 1 & $2 \mathrm{SG}$ & $2 \mathrm{SG}$ & \\
2 & $3 \mathrm{SG}$ & $3 \mathrm{PL}$ & $\mathrm{A}$ \\
3 & $3 \mathrm{PL}$ & $3 \mathrm{SG}$ & \\
\hline 4 & $2 \mathrm{PL}$ & $1 \mathrm{PL}$ & \\
5 & $1 \mathrm{PL}$ & $1 \mathrm{SG}$ & $\mathrm{B}$ \\
6 & $1 \mathrm{SG}$ & $2 \mathrm{PL}$ & \\
\hline
\end{tabular}

7 According to Renzi \& Vanelli (1983: 130), the omission of SCLs also occurs in the Istrian variety of Rovinj (Croatia). More generally, Heap (2000: 131 , 149) claims that in some Central Romance varieties negation particles may exhibit a blocking effect for SCLs in preverbal position.

8 On the grounds of the feature geometry postulated by Harley \& Ritter (2002), Heap (2002) claims that the special role of the 2 SG pronoun in 
For Friulian, this classification will be corroborated by the empirical data presented in the next section.

A certain range of optionality in realizing the SCLS is also attested by Marchetti (1952: 225). The author assumes that this is due to some, not further specified, euphonic reason. According to Marchetti (ibid.), it is possible to realize the SCL or to omit it for most persons, e.g. for 1SG (8a). In contrast, realization of the $2 \mathrm{SG}$ SCL is obligatory $(8 \mathrm{~b})$ :

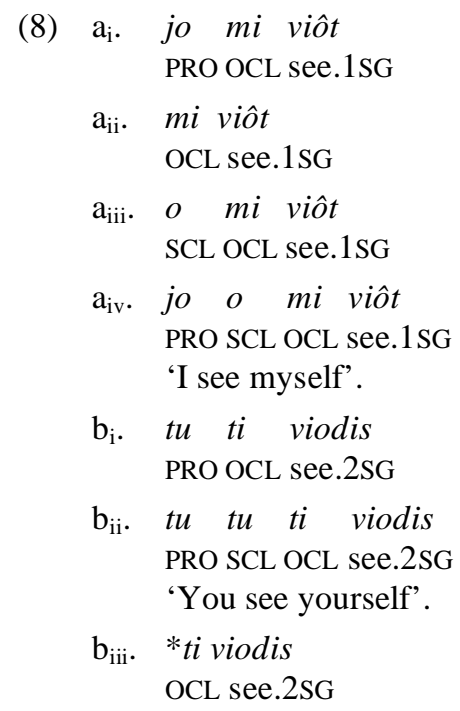

\section{Research questions and method}

The aim of the present paper is to provide a solution to the problem of SCL omission in Friulian. With this aim in mind I carried out fieldwork investigating grammaticality judgements in the main varieties of Friulian. The following distributional aspects were addressed:

(9) Degree of SCL realization:

(9a) in contexts without negation or OCLS

(= default context)

Central Romance languages is due to its feature underspecification in the lexicon. A discussion is provided in Hack \& Gaglia (2009). 
(9b) in the presence of the negation particle

(9c) in the presence of an OCL or reflexive pronoun ${ }^{9}$

For each main variety, one point of investigation was chosen. These points of investigation were Ampezzo (Carnic), Clauzetto (Western Friulian), and Mortegliano (Central-Southern Friulian). ${ }^{10}$ A questionnaire concerning grammaticality judgements was submitted to 52 speakers of Friulian. ${ }^{11}$ The speakers were randomly chosen with respect to age. The questionnaire consisted of 56 items and was structured as follows: for each grammatical person, and with respect to the different environments in question, two alternative sentences were presented to the speaker. The first sentence (10a) contained a SCL. The alternative sentence (10b) did not:

(10a) Vuê no o ai durmît ben ${ }^{12}$

(10b) Vuê no ai durmît ben

Both sentence types were presented to the speakers in written form as well as orally. In oral presentation and concerning presence of SCLs as in (10a), the SCL in question was stressed in a second repetiton of the whole sentence to guarantee that the speakers were aware of the targeted problem. The environments for distribution of SCLs were chosen as follows: ${ }^{13}$
(11a) SCL in default context:
8 items
(11b) SCL in negation context:
22 items
(11c) SCL with OCL/reflexive pronoun:
21 items

9 Due to considerations of convenience and for grammatical reasons, I treat reflexive pronouns together with OCLs.

10 The dominant Central-Southern Friulian variety is spoken in the area around Udine and in its suburbs. Nonetheless, I chose Mortegliano as point of investigation, since the pressure from Standard Italian onto Udinese is very remarcable.

11 Number of speakers involved: Ampezzo 21, Clauzetto 11, Mortegliano 20.

12 'Today, I did not sleep well'.

13 The number of items depends on grammatical person. In the default context, one item was chosen for each grammatical person. Three items for each grammatical person were chosen with respect to negation, except $2 \mathrm{SG}$, which was tested with two items. SCLs in the context of OCLs/reflexive pronouns were tested with three items for each grammatical person. 


\section{S. GAGLIA}

For each item, the speaker was required to give a grammaticality judgement. The possible answers were the following, with respect to $(7 \mathrm{a}, \mathrm{b})$ :

(12) A. I would use only a.

B. Preference for $a$. over $b$.

C. Preference for b. over a.

D. I would use only b.

E. Both a. and b. can be used unproblematically.

F. Neither a. nor b., but...

\subsection{Empirical results}

The average percentages for SCL realization in default contexts in the three varieties show that even in default contexts SCLS may be omitted (see Table 3). However, SCL realization for 2 SG, $3 \mathrm{SG}$ and $3 \mathrm{PL}$ is much higher than for $2 \mathrm{PL}, 1 \mathrm{SG}$ and $1 \mathrm{PL}$. The $2 \mathrm{SG}$ SCL was realized in a default context in $84.19 \%$ of cases; moreover, in a further $3.03 \%$ its realization was preferred. This implies that SCL omission is marginally accepted even in this context. This may be due to socio-linguistic factors, which are not under examination here, as well as to contact with Standard Italian. The percentages for the SCLs of $1 \mathrm{SG}, 1 \mathrm{PL}$ and $2 \mathrm{PL}$ are significantly lower, but still quite high in comparison with the results in blocking environments (see Tables 7 and 11).

Table 3. SCLs in default contexts (average percentages for Friulian)

\begin{tabular}{c|rrrrrrr}
\hline answer & \multicolumn{1}{|c}{ 1SG } & \multicolumn{1}{c}{ 2SG } & 3 M.SG & 3F.SG & 1PL & \multicolumn{1}{c}{ 2PL } & \multicolumn{1}{c}{ 3PL } \\
\hline $\mathrm{A}$ & 30.44 & $\mathbf{8 4 . 1 9}$ & $\mathbf{8 0 . 8 7}$ & 55.58 & 21.19 & 45.51 & $\mathbf{7 2 . 5 3}$ \\
$\mathrm{B}$ & 1.67 & $\mathbf{3 . 0 3}$ & $\mathbf{1 . 5 9}$ & 7.73 & 5.0 & 5.0 & $\mathbf{7 . 3}$ \\
$\mathrm{C}$ & 6.36 & 0.0 & 0.0 & 0.0 & 10.67 & 3.03 & 1.67 \\
$\mathrm{D}$ & 37.93 & 3.17 & 1.59 & 11.27 & 28.17 & 19.44 & 3.17 \\
$\mathrm{E}$ & 12.41 & 3.25 & 9.6 & 8.09 & 14.16 & 9.68 & 8.06 \\
$\mathrm{~F}$ & 9.6 & 6.35 & 6.35 & 15.66 & 20.73 & 17.33 & 7.27 \\
\hline
\end{tabular}

Tables 4, 5 and 6 display the results for each variety. The variation concerns a clearer dichotomy between usage and nonusage of SCLs in Clauzetto and Mortegliano, while the results for Ampezzo are lower. I assume, that the lower realization for Ampezzo is due to its geographical location, since the village has always been situated along a territory of transition between Italy 
The Omission of Preverbal Subject Clitics in Friulian

and Austria, which renders the varieties spoken in this region "neutral", according to (Francescato 1966b: 168).

Table 4. scls in default contexts (percentages for Ampezzo)

\begin{tabular}{c|ccccccc}
\hline answer & 1SG & 2SG & 3M.SG & 3F.SG & 1PL & 2PL & 3PL \\
\hline A & 19.05 & $\mathbf{6 6 . 6 7}$ & $\mathbf{4 7 . 6 2}$ & 38.1 & 28.57 & 23.81 & $\mathbf{5 7 . 1 4}$ \\
B & 0.0 & $\mathbf{0 . 0}$ & $\mathbf{4 . 7 7}$ & 0.0 & 0.0 & 0.0 & $\mathbf{1 1 . 9}$ \\
C & 0.0 & 0.0 & 0.0 & 0.0 & 0.0 & 0.0 & 0.0 \\
D & 33.33 & 9.52 & 4.77 & 23.81 & 19.05 & 33.33 & 9.52 \\
E & 19.05 & 4.76 & 23.81 & 14.29 & 14.29 & 19.05 & 16.67 \\
F & 23.81 & 19.05 & 19.05 & 23.81 & 38.1 & 23.81 & 4.76 \\
\hline
\end{tabular}

Table 5. SCLs in default contexts (percentages for Clauzetto)

\begin{tabular}{c|ccccccc}
\hline answer & 1SG & 2SG & 3M.SG & 3F.SG & 1PL & 2PL & 3PL \\
\hline A & 27.27 & $\mathbf{9 0 . 9}$ & $\mathbf{1 0 0 . 0}$ & 63.64 & 0.0 & 72.73 & $\mathbf{9 5 . 4 5}$ \\
B & 0.0 & $\mathbf{9 . 0 9}$ & 0.0 & 18.18 & 0.0 & 0.0 & 0.0 \\
C & 9.09 & 0.0 & 0.0 & 0.0 & 27.27 & 9.09 & 0.0 \\
D & 45.45 & 0.0 & 0.0 & 0.0 & 45.45 & 0.0 & 0.0 \\
E & 18.18 & 0.0 & 0.0 & 0.0 & 18.18 & 0.0 & 0.0 \\
F & 0.0 & 0.0 & 0.0 & 18.18 & 9.09 & 18.18 & 4.55 \\
\hline
\end{tabular}

Table 6. SCLs in default contexts (percentages for Mortegliano)

\begin{tabular}{c|ccccccc}
\hline answer & 1SG & 2SG & 3M.SG & 3F.SG & 1PL & 2PL & 3PL \\
\hline A & 45.0 & $\mathbf{9 5 . 0}$ & $\mathbf{9 5 . 0}$ & 65.0 & 35.0 & 40.0 & 65.0 \\
B & 5.0 & 0.0 & 0.0 & 5.0 & 15.0 & 15.0 & 10.0 \\
C & 10.0 & 0.0 & 0.0 & 5.0 & 5.0 & 0.0 & 5.0 \\
D & 35.0 & 0.0 & 0.0 & 10.0 & 20.0 & 25.0 & 0.0 \\
E & 0.0 & 5.0 & 5.0 & 10.0 & 10.0 & 10.0 & 7.5 \\
F & 5.0 & 0.0 & 0.0 & 5.0 & 15.0 & 10.0 & 12.5 \\
\hline
\end{tabular}

Clearer are the contrasts of SCL realization and omission in the context of negation (see averages in Table 7). There is significant realization of the SCLs of $2 \mathrm{SG}$ and $3 \mathrm{M} . \mathrm{SG}$, whereas the SCLs of the other persons are omitted to a significant extent. It is not surprising that the 3F.SG SCL patterns together with 1SG, 1PL, $2 \mathrm{PL}, 3 \mathrm{PL}$, since it is purely vocalic (see previous sections). This is not the case for $3 \mathrm{M} . \mathrm{SG}$, which tends to be realized due to its partial consonantal status (cf. Hack \& Gaglia 2009). 
Interestingly, in $14.11 \%$ of the items concerning the 2SG SCL, this clitic was omitted (answer D). This may be due to the strong impact of Italian, which does not exhibit SCLs. However, this suggestion is certainly ad hoc and needs more investigation.

Table 7. SCLs in the context of negation (average percentages for Friulian)

\begin{tabular}{c|rrrrrrr}
\hline answer & 1SG & \multicolumn{1}{c}{ 2SG } & 3M.SG & 3F.SG & 1PL & 2PL & \multicolumn{1}{c}{ 3PL } \\
\hline A & 1.06 & $\mathbf{7 5 . 7}$ & $\mathbf{4 8 . 6 4}$ & 0.53 & 0.53 & 0.56 & 3.23 \\
B & 5.83 & $\mathbf{6 . 1 3}$ & $\mathbf{8 . 4}$ & 4.87 & 4.87 & 4.87 & 5.59 \\
C & 4.63 & 0.0 & 2.67 & 2.17 & 2.6 & 3.76 & 1.09 \\
D & 80.5 & $\mathbf{1 4 . 1 1}$ & 17.81 & 79.2 & 80.95 & 81.75 & 72.81 \\
E & 3.18 & 1.67 & 7.95 & 2.07 & 3.17 & 1.64 & 2.89 \\
F & 4.79 & 2.38 & 12.94 & 7.87 & 7.87 & 6.3 & $\mathbf{1 3 . 3}$ \\
\hline
\end{tabular}

Some attention should be drawn to the answers indicated with $\mathrm{F}$, which means that the speaker did not agree with either of the options provided. Speakers answering in favour of F did so mostly (a) because of phonological variation within a given sentence, which were judged as ungrammatical by the speakers, or (b) due to the prenegative position of the 3PL SCL in the context of negation. ${ }^{14}$ In this context $13.3 \%$ of the speakers who indicated $\mathrm{F}$ preferred an answer of the kind shown in (13a), where the SCL is realized in prenegative position.

(13a) Marie e Paulia no vegnin.

Mary and Paul SCL NEG come-3PL

(13b) Marie e Pauli no vegnin.

Mary and Paul NEG come-3PL

(13c) \%Marie e Pauli no a vegnin.

Mary and Paul NEG SCL come-3PL

'Mary and Paul do not come.'

14 Suffice it to say that interference may be due to diatopic phonological variation, e.g. 1PL SCL vualtro $\int$ (Ampezzo), vuatros (Clauzetto), vualtris (Mortegliano). 
The preferred answer includes omission of the SCL in the given context (13b), while the sentence in (13c) was tendentially excluded. ${ }^{15}$ I will claim, that this is the result of a phonological constraint, which bans to adjacent vowels in a given prosodic domain. Moreover, I will show, that prenegative realization as in (13a) is due to syncretism avoidance concerning whole SCL$\mathrm{V}$-sequences, but only for 3PL. Elsewhere, prenegative realization does not occur. I assume that the number of responses in favour of prenegative SCL realization would be significantly higher if that option had been explicitly indicated in the questionnaire. Since postnegative realization and omission were the only possibilities investigated, however, this option was not provided.

The usage of SCLs for $2 \mathrm{SG}$ and 3M.SG in negative contexts is significantly higher for Mortegliano (see Table 10), than for Ampezzo (Table 8) and Clauzetto (Table 9).

Table 8. sCLs in negative contexts (percentages for Ampezzo)

\begin{tabular}{c|rrrrrrr}
\hline answer & \multicolumn{1}{|c}{ 1SG } & \multicolumn{1}{c}{ 2SG } & 3M.SG & 3F.SG & 1PL & 2PL & \multicolumn{1}{c}{ 3PL } \\
\hline A & 3.17 & $\mathbf{7 1 . 4 3}$ & 30.16 & 1.59 & 1.59 & 0.0 & 0.0 \\
B & 4.76 & $\mathbf{4 . 7 6}$ & 4.76 & 1.59 & 1.59 & 1.59 & 2.38 \\
C & 3.13 & 0.0 & 6.35 & 3.17 & 4.76 & 1.59 & 1.59 \\
D & 73.02 & 16.67 & 28.57 & 87.3 & 79.37 & 85.71 & 84.17 \\
E & 3.17 & 0.0 & 11.11 & 3.17 & 3.17 & 1.59 & 3.97 \\
F & 12.7 & 7.14 & 14.29 & 3.17 & 9.52 & 7.94 & 7.94 \\
\hline
\end{tabular}

Table 9. SCLs in negative contexts (percentages for Clauzetto)

\begin{tabular}{c|rrrrrrr}
\hline answer & \multicolumn{1}{|c}{ 1SG } & \multicolumn{1}{c}{ 2SG } & 3M.SG & 3F.SG & 1PL & 2PL & \multicolumn{1}{c}{ 3PL } \\
\hline A & 0.0 & $\mathbf{6 8 . 1 8}$ & 42.42 & 12.12 & 0.0 & 0.0 & 3.03 \\
B & 6.06 & $\mathbf{1 3 . 6 4}$ & 12.12 & 6.06 & 3.03 & 3.03 & 6.06 \\
C & 9.09 & 0.0 & 0.0 & 0.0 & 3.03 & 3.03 & 0.0 \\
D & 81.82 & 18.18 & 18.18 & 63.64 & 81.82 & 87.88 & 57.58 \\
E & 3.03 & 0.0 & 6.06 & 3.03 & 3.03 & 0.0 & 3.03 \\
F & 0.0 & 0.0 & 21.21 & 15.15 & 9.09 & 6.06 & 30.3 \\
\hline
\end{tabular}

15 I mark the example in (13c) with \%, due to the clear tendency to avoid adjacent vowels in this particular context. Since $3.23 \%$ of the cases display answer A and in $5.59 \%$ of the cases the presence of SCL is preferred, it would not be opportune to classifiy these results as ungrammatical. 


\section{S. GAGLiA}

Table 10. SCLs in negative contexts (percentages for Mortegliano)

\begin{tabular}{c|rrrrrrr}
\hline answer & \multicolumn{1}{|c}{ 1SG } & \multicolumn{1}{c}{ 2SG } & 3M.SG & 3F.SG & 1PL & 2PL & \multicolumn{1}{c}{ 3PL } \\
\hline A & 0.0 & $\mathbf{8 7 . 5}$ & $\mathbf{7 3 . 3 3}$ & 0.0 & 0.0 & 1.67 & 6.67 \\
B & 6.67 & $\mathbf{0 . 0}$ & $\mathbf{8 . 3 3}$ & 10.0 & 10.0 & 10.0 & 8.33 \\
C & 1.67 & 0.0 & 1.67 & 1.67 & 0.0 & 6.67 & 1.67 \\
D & 86.67 & 7.5 & 6.67 & 86.67 & 81.67 & 71.67 & 76.67 \\
E & 3.33 & 5.0 & 6.67 & 0.0 & 3.33 & 3.33 & 1.67 \\
F & 1.67 & 0.0 & 3.33 & 1.67 & 5.0 & 5.0 & 4.17 \\
\hline
\end{tabular}

As expected, in the context of an OCL or a reflexive pronoun, SCLs are mostly realized with respect to $2 \mathrm{SG}$ but tend to be deleted in the rest of the paradigm.

Table 11. SCLs in the context of OCLs/reflexive pronouns (average percentages for Friulian)

\begin{tabular}{c|rrrrrrr}
\hline answer & \multicolumn{1}{|c}{ 1SG } & \multicolumn{1}{c}{ 2SG } & 3M.SG & 3F.SG & 1PL & 2PL & \multicolumn{1}{c}{ 3PL } \\
\hline A & 1.11 & $\mathbf{6 2 . 1 4}$ & 10.69 & 2.64 & 1.67 & 1.06 & 21.27 \\
B & 2.78 & $\mathbf{5 . 3 7}$ & 6.51 & 3.84 & 3.35 & 7.65 & 6.01 \\
C & 8.56 & 1.23 & 4.39 & 2.14 & 3.73 & 3.07 & 5.98 \\
D & 77.91 & 10.16 & 47.51 & 68.55 & 69.76 & 80.28 & 39.63 \\
E & 3.75 & 6.4 & 23.49 & 9.58 & 6.38 & 3.7 & 17.79 \\
F & 5.85 & 13.25 & 6.35 & 6.34 & 13.19 & 8.8 & 13.56 \\
\hline
\end{tabular}

The diatopic variation is displayed in Tables 12, 13 and 14. Again, the data from Mortegliano show higher results in favour of SCL-realization with respect to $2 \mathrm{SG}$ than the other two varieties with respect to the distribution of SCLS with OCLs.

Table 12. SCLs in OCL contexts (percentages for Ampezzo)

\begin{tabular}{c|rrrrrrr}
\hline answer & \multicolumn{1}{|c}{ 1SG } & \multicolumn{1}{c}{ 2SG } & 3M.SG & 3F.SG & 1PL & 2PL & 3PL \\
\hline A & 0.0 & $\mathbf{5 2 . 3 8}$ & 12.7 & 4.76 & 0.0 & 3.17 & 38.1 \\
B & 0.0 & $\mathbf{6 . 3 5}$ & 4.76 & 1.59 & 3.17 & 1.59 & 2.38 \\
C & 9.52 & 1.59 & 1.59 & 1.59 & 3.17 & 3.17 & 4.76 \\
D & 79.37 & 11.11 & 41.27 & 60.32 & 50.8 & 65.08 & 35.71 \\
E & 4.76 & 7.94 & 28.57 & 12.7 & 11.11 & 11.11 & 15.87 \\
F & 7.94 & 20.63 & 9.52 & 17.46 & 28.57 & 14.29 & 18.25 \\
\hline
\end{tabular}


The Omission of Preverbal Subject Clitics in Friulian

Table 13. SCLs in OCL contexts (percentages for Clauzetto)

\begin{tabular}{c|rrrrrrr}
\hline answer & \multicolumn{1}{|c}{ 1SG } & \multicolumn{1}{c}{ 2SG } & 3M.SG & 3F.SG & 1PL & 2PL & \multicolumn{1}{c}{ 3PL } \\
\hline A & 0.0 & $\mathbf{5 2 . 3 8}$ & $\mathbf{1 2 . 7}$ & $\mathbf{3 . 1 7}$ & 0.0 & 0.0 & $\mathbf{1 9 . 0 5}$ \\
B & 0.0 & $\mathbf{4 . 7 6}$ & $\mathbf{4 . 7 6}$ & $\mathbf{1 . 5 9}$ & 3.03 & 3.03 & $\mathbf{3 . 9 7}$ \\
C & 9.5 & 1.59 & 1.59 & 3.17 & 3.03 & 3.03 & 3.17 \\
D & 79.37 & 12.7 & 41.27 & 60.32 & 81.82 & 87.88 & 36.51 \\
E & 3.17 & 7.94 & 28.57 & 12.7 & 3.03 & 0.0 & 16.67 \\
F & 7.94 & 17.46 & 9.52 & 17.46 & 9.09 & 6.06 & 18.25 \\
\hline
\end{tabular}

Table 14. SCLs in ocl contexts (percentages for Mortegliano)

\begin{tabular}{c|rrrrrrr}
\hline answer & 1SG & 2SG & 3M.SG & 3F.SG & 1PL & 2PL & \multicolumn{1}{c}{ 3PL } \\
\hline A & 3.33 & $\mathbf{8 1 . 6 7}$ & 6.67 & 0.0 & 5.0 & 0.0 & 6.67 \\
B & 8.33 & $\mathbf{5 . 0}$ & 10.0 & 8.33 & 6.67 & 3.03 & 11.67 \\
C & 6.67 & 3.33 & 10.0 & 1.67 & 5.0 & 3.03 & 10.0 \\
D & 75.0 & 6.67 & 60.0 & 85.0 & 76.67 & 87.88 & 46.67 \\
E & 3.33 & 3.33 & 13.33 & 3.33 & 5.0 & 0.0 & 20.83 \\
F & 1.67 & 1.67 & 0.0 & 0.0 & 1.67 & 6.06 & 4.17 \\
\hline
\end{tabular}

\subsection{Methodological remarks and results on written Friulian}

Grammaticality judgements by themselves can only give a restricted picture of linguistic reality, since the speaker's natural realization of a sentence may deviate from the alternatives given to him/her during a grammaticality judgement test. Moreover, there are several factors which have to be controlled for in such a test, e.g. diatopic phonological variation (see footnote 14). For a representative picture of the phenomenon it is therefore necessary to combine different methods, i.e. to carry out a thorough corpus analysis as well as elicitation tasks.

As a starting point for the present study, a small corpus has been analysed, consisting of chapter 1 Samuel 1-3 from a Friulian bible (see Bibie). The corpus includes a total of 85 verses, 155 sentences and 2,649 words. The bible is written in the modern Central-Southern Friulian koiné. The advantage of using biblical passages is that different languages and varieties can thus be compared on the basis of a single text. An obvious disadvantage, however, is the potential standardization of the written form. This does not reflect the existence of 
optionality or speaker preferences in the spoken language, which is crucial for our purpose of determining the true extent of SCL realization and how it may diverge with respect to the grammatical person and to adjacency. For the written corpus I expected stable results, i.e. no variation regarding the presence or absence of SCLs: this is corroborated by the data. Nonetheless, the following results do give us an impression of the margins for variation and allow us to compare spoken and written Friulian.

First, in the written corpus, SCLs occur regularly within default contexts. Second, in the context of negation, SCLs other than 2SG and 3M.SG are never realized (see Table 15, a.). Third, in the context of an object clitic, SCLs other than $2 \mathrm{SG}$ is realized one time $(=1.6 \%$; see Table $15, b$. $)$. Fourth, in the context of a reflexive pronoun, SCLs are never realized (see Table 15, c.) Fifth, SCLs are always adjacent to the verb. Realization of SCLS in prenegative position is not observed, e.g. for 3PL (see Table 15, d.), which is consistent with the findings given in Friulian grammars. Neither Marchetti (1952), nor Douglas (1977) or Vicario (2005) mention any sign of variation here. On the other hand, in her thesis Brovedani (1981: 80-83) observes prenegative SCL realization not only with respect to 3PL but also regarding 3M.SG and 3F.SG for Clauzetto. ${ }^{16}$ This finding was not replicated in my own investigation. The following Table summarizes the findings from the bible corpus.

Table 15. Bible corpus

\begin{tabular}{|c|c|c|c|}
\hline \multirow{2}{*}{ Type } & \multirow{2}{*}{ Tokens } & \multicolumn{2}{|c|}{ SCL-realization } \\
\hline & & Total numbers & percentage \\
\hline $\begin{array}{l}\text { a. } \mathrm{NEG}+\mathrm{SCL} \\
\quad(\mathrm{SCL} \neq 2 \mathrm{SG}, 3 \mathrm{MSG})\end{array}$ & 14 & 0 & $0.0 \%$ \\
\hline b. $\mathrm{SCL}+\mathrm{OCL}(\mathrm{SCL} \neq 2 \mathrm{SG})$ & 65 & 1 & $1.6 \%$ \\
\hline c. $\mathrm{SCL}+\mathrm{REF}(\mathrm{SCL} \neq 2 \mathrm{SG})$ & 16 & 0 & $0.0 \%$ \\
\hline d. SCL+NEG & 7 & 0 & $0.0 \%$ \\
\hline
\end{tabular}

16 With respect to Friulian varieties, which show prenegative realization in 3SG, see also Benincà (2005: 49). 
Of course, a small corpus like this one, which involves data from a narrative text, is not able to capture all possible SCL configurations. Bear in mind that the SCL which occurs most should be one of the 3SG forms (112 realized tokens), since the role of a character in narrative is that of a third person from the point of view of the narrator. Hence, the study of a large spoken corpus is necessary. ${ }^{17}$

\section{Constraint-based analysis}

In this section, I will analyze the data presented in the previous sections in terms of the standard version of Optimality Theory (OT, McCarthy \& Prince 1993, Prince \& Smolensky 1993), which offers a fruitful way to study the complex problem of Friulian SCL omission. OT is a framework that ranks universal and language-specific constraints on the output generated by its machinery from a given lexical representation, the input. These constraints represent the conflicting principles of markedness and faithfulness. While faithfulness means that an output may not deviate from a given input, markedness constraints refer only to output forms, with reference to their well-formedness. Constraints may be satisfied or violated by an output. The best of all possible output forms with respect to the constraint ranking is evaluated as the optimal candidate. For Friulian SCL omission, I will postulate the following constraint ranking, which I explain below.

17 Since syncretism plays an important role with respect to SCL deletion in Friulian, as we will see, the phenomenon must also be studied empirically in detail. A second questionnaire involving an elicitation task was therefore submitted to the speakers. The targets were syncretic verbs with respect to the blocking environment studied here. In doing this, I expected to find additional evidence for the claims stated above on the basis of grammaticality judgements. The questionnaire was submitted to 26 speakers of Friulian in the three main varieties. Again, Ampezzo and Clauzetto were chosen as points of investigation for Carnic and Western Friulian. The data regarding Central-Southern Friulian were retrieved from speakers in Cusignacco, San Daniele del Friuli, and Campoformido. The questionnaire contained 20 to 26 sentences depending on the variety, the differences being due to diatopic variation in the manifestation of syncretism. The data are still under analysis. 


\section{S. GAGLIA}

(14) *VV]cg > Ident-IO(neg) > Max(scl2sg,3m.sg,3pl) > Linearity IO $>$ Max $(\mathrm{scl})$

These constraints can be defined as follows:

(15) $\quad * \mathrm{VV}]_{\mathrm{CG}}$ :

Adjacent vowels are not allowed within a clitic group.

$\operatorname{Ident}-\mathrm{IO}(n o)$ :

Input and output of the negation particle $/ \mathrm{no} /$ have to be identical.

$\operatorname{Max}\left(\mathrm{SCL}_{2 \mathrm{SG}, 3 \mathrm{M} . \mathrm{SG}, 3 \mathrm{pL}}\right)$ :

Realize the SCL of 2SG, 3M.SG and 3PL.

Linearity-IO:

The surface representation negation particles, clitics and verbs corresponds to their linear ordering in the input.

$\operatorname{Max}(\mathrm{SCL})$ :

SCL-omission is not allowed with respect to the output.

This ranking is exemplified in Tables 16 and 17, by /no a kjantavin/ (NEG SCL sing-3PL IMPF.IND) and /no i kjantavin/ (NEG SCL sing-1PL IMPF.IND). ${ }^{18}$

Table 16. OT analysis for /no a kjantavin/ (IMPF.3PL)

\begin{tabular}{|c|c|c|c|c|c|}
\hline /no a kjantavin/ & $\sum_{*}^{0}$ & 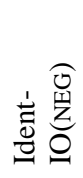 & 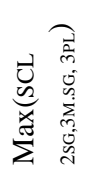 & 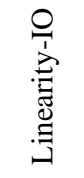 & 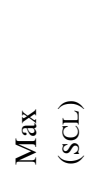 \\
\hline no a kjantavin & $* !$ & & & & \\
\hline $\mathrm{n}$ a kjantavin & & $* !$ & & & \\
\hline no kjantavin & & & $* !$ & & $*$ \\
\hline$\approx$ a no kjantavin & & & & $*$ & \\
\hline no kjantavin a & & & & $* * !$ & \\
\hline kjantavin a no & & & & $* * * !$ & \\
\hline kjantavin no a & $* !$ & & & $* * *$ & \\
\hline
\end{tabular}

18 I will neglect word stress in phonetic transcriptions as well as in the phonological representations. 
The Omission of Preverbal Subject Clitics in Friulian

Table 17. OT analysis for /no i kjantavin/ (IMPF.1PL)

\begin{tabular}{|c|c|c|c|c|c|}
\hline /no i kjantavin/ & $\sum_{*}^{0}$ & 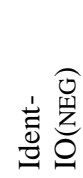 & 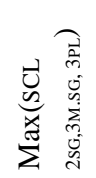 & 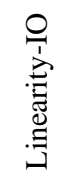 & 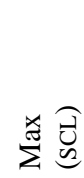 \\
\hline no i kjantavin & $* !$ & & & & \\
\hline $\mathrm{n}$ i kjantavin & & $* !$ & & & \\
\hline no kjantavin & & & & & * \\
\hline i no kjantavin & & & & $*$ & \\
\hline no kjantavin $\mathrm{i}$ & & & & $* * !$ & \\
\hline kjantavin i no & & & & $* * * !$ & \\
\hline kjantavin no i & $* !$ & & & $* * *$ & \\
\hline
\end{tabular}

In both cases, the SCL is omitted in postnegative position.

From my point of view this is clearly due to phonology. Hence, a phonological constraint $* \mathrm{VV}]_{\mathrm{CG}}$ bans the occurrence of two adjacent vowels, i.e. *no $i$, *no $a$. The phenomenon is situated in a preverbal domain which, following Nespor \& Vogel (2007), I will call the clitic group (CG). The CG contains the verb as well as all clitics which are associated with it (cf. Nespor \& Vogel 2007: 154) and it provides the domain for phonological processes concerning clitics. This points in the same direction as Haiman \& Benincà (1992: 179), who claim that SCL omission in Ladin and Friulian before vowel-initial verbs is due to an originally phonetic process. Therefore I assume that $* \mathrm{VV}]_{\mathrm{CG}}$ prevents two adjacent vowels to occur in CG-internal position, and triggers, thereby, postnegative SCL omission (see Tables 16 and 17). $\left.{ }^{*} \mathrm{VV}\right]_{\mathrm{CG}}$ is the highest constraint with respect to omission. This is empirically confirmed, since all vocalic SCLs undergo postnegative omission.

Ident-IO(NEG) is a faithfulness constraint which impedes deletion of a segment from the negation particle no, since it is the vocalic SCL which undergoes omission in postnegative position. Identity is guaranteed for no with respect to the input. This can be observed with respect to those clusters consisting of the negation particle and of the reduced masculine singular SCL $l(/ \mathrm{al} /)$. So-called aphesis, i.e. the deletion of an initial vowel, is 
quite surprising in this regard ( $n o l$ is found rather than *nal), because the behaviour of other clitic sequences, such as OCLOCL, would lead us to expect apocope (deletion of a final vowel) rather than aphesis (cf. Hack \& Gaglia 2009: 177; the output forms in (16) are taken from Gregor 1975: 112):

\begin{tabular}{|c|c|c|c|c|}
\hline (16a) & $\begin{array}{l}m i \\
\text { DAT .1SG }\end{array}$ & + & $\begin{array}{l}a l \\
\text { ACC.M.SG }\end{array}$ & $\rightarrow$ \\
\hline (16b) & $t i$ & + & $e$ & $\rightarrow$ \\
\hline
\end{tabular}

But apocope is never observed with respect to the NEG-SCL sequence. The reason why the SCL $a l$ is not deleted completely in the context of negation is simply its possession of a coda. Ident-IO(NEG) is dominated by $* \mathrm{VV}]_{\mathrm{CG}}$.

$\operatorname{Max}\left(\mathrm{SCL}_{2 \mathrm{SG}, \mathrm{M} . \mathrm{SG}, 3 \mathrm{PL}}\right)$ prevents syncretism from output forms, when the cells of $2 \mathrm{SG}, 3 \mathrm{M} . \mathrm{SG}$ or $3 \mathrm{PL}$ are involved in distribution with the negation particle. ${ }^{19}$ Syncretism (or homophony) means that one phonetic form is shared by at least two cells in the paradigm (cf. Spencer 1991, Trask 1997, Baerman et al. 2005, among others). The verb systems of the Friulian varieties are highly syncretic. On the one hand, homophony occurs in the paradigm of all moods and tenses (other than the present tense in the first conjugational class), e.g. ciantavin (sing-IMPF.1PL/3PL).

On the other hand, the SCLs of 1SG, 1PL and 2PL, which mostly undergo omission, are also homophonic (see Tables 1 and 2). From my point of view and against this backdrop, SCL omission seems to be a paradox, since SCLs play a crucial role in the disambiguation of verbal syncretism (see also Hack \& Gaglia 2009). ${ }^{20}$ This becomes more evident if one looks at the SCLs and verbs from a combinatorial perspective with respect to the three main varieties of Friulian. In Table 18, I use Greek characters to indicate the different SCLs $(\alpha, \beta, \gamma, \delta)$. The capital

19 Crosswhite (2001: 155-158) uses Anti-Ident as a syncretism preventing constraint with respect to vowel reduction in a Bulgarian variety.

20 Cf. also Marchetti (1952: 222) and Frau (1984: 74), who argue in favour of a disambiguating function for SCLS. 
$\mathrm{V}$ with numerals in subscript is used for the different verb forms, i.e. $\mathrm{V}_{1,2, \ldots, \mathrm{n}}$. According to this, the three main varieties exhibit four different SCLs, and 27 different verb forms. Cells with syncretic verb forms or syncretic clitics are darkened.

Table 18. Combinatorial pattern

\begin{tabular}{l|ccccccc}
\hline & SCL & $\begin{array}{c}\text { PRES } \\
<1>^{21}\end{array}$ & $\begin{array}{c}\text { PRES } \\
<2,3>\end{array}$ & $\begin{array}{c}\text { IMPF/ } \\
\text { PERF }\end{array}$ & $\begin{array}{c}\text { SUBJ. } \\
\text { IMP/ } \\
\text { COND }\end{array}$ & $\begin{array}{c}\text { SUBJ. } \\
\text { PRES }\end{array}$ & $\begin{array}{c}\text { FUT } \\
<4>\end{array}$ \\
\hline 1SG & $\alpha$ & $\mathrm{V}_{1}$ & $\mathrm{~V}_{7}$ & $\mathrm{~V}_{11}$ & $\mathrm{~V}_{15}$ & $\mathrm{~V}_{19}$ & $\mathrm{~V}_{24}$ \\
2SG & $\beta$ & $\mathrm{V}_{2}$ & $\mathrm{~V}_{8}$ & $\mathrm{~V}_{12}$ & $\mathrm{~V}_{16}$ & $\mathrm{~V}_{20}$ & $\mathrm{~V}_{25}$ \\
3M.SG & $\gamma$ & $\mathrm{V}_{3}$ & $\mathrm{~V}_{7}$ & $\mathrm{~V}_{13}$ & $\mathrm{~V}_{15}$ & $\mathrm{~V}_{19}$ & $\mathrm{~V}_{26}$ \\
3F.SG & $\delta$ & & $\mathrm{V}_{9}$ & $\mathrm{~V}_{14}$ & $\mathrm{~V}_{17}$ & $\mathrm{~V}_{21}$ & $\mathrm{~V}_{27}$ \\
1PL & $\alpha$ & $\mathrm{V}_{4}$ & $\mathrm{~V}_{10}$ & $\mathrm{~V}_{12}$ & $\mathrm{~V}_{18}$ & $\mathrm{~V}_{22}$ & $\mathrm{~V}_{28}$ \\
2PL & $\alpha$ & $\mathrm{V}_{5}$ & $\mathrm{~V}_{10}$ & $\mathrm{~V}_{14}$ & $\mathrm{~V}_{17}$ & $\mathrm{~V}_{23}$ & $\mathrm{~V}_{27}$ \\
3PL & $\delta$ & $\mathrm{V}_{6}$ & $\mathrm{~V}_{7}$ & & & & \\
\hline
\end{tabular}

Since syntagmatic (or combinatorial) syncretism is observable only with respect to the SCL-verb sequence $\delta-\mathrm{V}_{7}$ in Ampezzo and Clauzetto (i.e. 3F.SG/3PL SCL and the 3SG/3PL verb form of the second and third conjugational class), which may be avoided through SCL omission-syncretism avoidance obviously plays some psychological role in the system of Friulian. A further argument to favour this hypothesis is prenegative SCL realization. It is crucial that in the varieties studied with the present paper, the SCL of 3PL may be realized in prenegative position (13a).

Similarly, this phenomenon is also attested by Poletto (2000: 18-20, 32-35) for NIDs, as her examples from Loreo (Southern Veneto) show. Prenegative SCLs occur for 1SG (17a) but not for 3F.SG (17b):

\section{(17a) $\boldsymbol{A}$ no vegno. \\ SCL not come}

'I do not come'.

21 I use numerals in angled brackets to indicate conjugational class, i.e. $\langle 1\rangle=$ first class, $\langle 2,3\rangle=$ second and third class, $\langle 4\rangle=$ fourth class. 


\section{S. GAGLIA}

(17b) No la vien.

not SCL come

'She does not come'.

Poletto (2000: 19-20) assumes that the agreement field "contains two SCL positions, a prenegative and a postnegative", and that the prenegative position is occupied by invariable and deictic SCLs, while in postnegative position person and number SCLs are merged. Invariable SCLs are syncretic over all persons, while deictic SCLs draw a distinction between persons involved in the conversation (first and second person) and those who are excluded (third person). For example, the Swiss Lombard variety of Lugano exhibits $a$ as SCL for each person in the paradigm. Similarly, the Friulian variety of S. Michele al Tagliamento draws a deictic distinction between the SCL of the first and second person, which is $i$, vs. the SCL of the third person, which is realized by $a$ : the distinction is thus based on the feature [ \pm hearer]. The postnegative person/number SCLs, on the other hand, exhibit oppositions between singular/plural, hearer/non-hearer, masculine/feminine etc., e.g. $2 \mathrm{SG}: t+\mathrm{V}$, 3M.SG: V+l. Poletto (2000: 21) gives the following syntactic structure for SCLs in the context of a negation particle: ${ }^{22}$

$$
\begin{aligned}
& \text { [FP1 invariable SCLs/deictic SCLS } \\
& \text { [NEGP [FP2 number SCLs/person SCLs]]] }
\end{aligned}
$$

The data show that the realization and the position of SCLs in Friulian corresponds, although not completely, to the basic assumptions in Poletto (2000) with respect to negation. I claim that prenegative realization of the SCL represents a strategy for avoiding syncretism. The following examples show that prenegative realization prevents syncretism between 1PL and 3PL, e.g. with respect to the imperfect indicative. As mentioned above, *[no $\mathbf{i}$ kjantavin] (orth. *no i ciantavin) is ungrammatical due to $* \mathrm{VV}]_{\mathrm{CG}}$. Hence, the $1 \mathrm{PL}$ SCL is omitted in postnegative position.

22 Remember, that there are actually four FPs. Within a FP, the SCLs cannot co-occur. 
The Omission of Preverbal Subject Clitics in Friulian

(19)

$$
\begin{array}{ll}
*[\text { no i kjantavin }] & \left.(* \mathrm{VV}]_{\mathrm{CG}}\right) \\
\rightarrow & {[\text { no kjantavin }]} \\
& \text { NEG sing-1PL IMPF. IND. } \\
& \text { 'We do not sing'. }
\end{array}
$$

The example in (20) shows the ungrammatical sequence NEG3 PL *no a kjantavin. Again, the SCL is omitted to satisfy $* V V V]_{\mathrm{CG}}$. The result is a syncretic SCL-Verb sequence with respect to 1PL. In order to satisfy $\operatorname{Max}\left(\mathrm{SCL}_{2 \mathrm{SG}, 3 \mathrm{M} . \mathrm{SG}, 3 \mathrm{PL}}\right)$, the $\mathrm{SCL}$ of 3PL may be realized prenegatively, which means, that the SCL moves from its postnegative position in front of the negation particle.

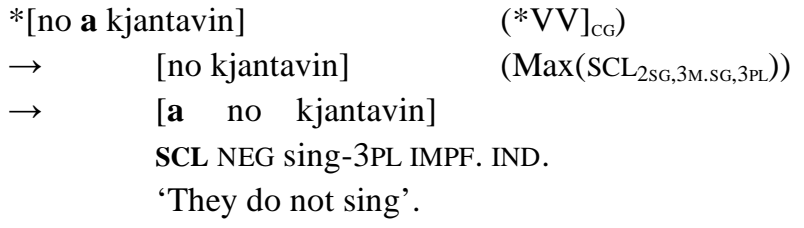

Coming back to Poletto's data from Loreo, I hypothesize that if $* \mathrm{VV}]_{\mathrm{CG}}$ is active and ranked high, then the prenegative SCL realization may be a result of this constraint, which would be comparable to the situation regarding 3PL in Friulian. Since I do not know the data from Loreo, it would be interesting to know whether an anti-syncretism constraint is also relevant within this variety and how it interacts with other constraints. If prenegative realization is generally observable for vocalic SCLS in Loreo in the context of negation then I assume syncretism avoidance plays no role at all or is ranked low. An important question to answer is, how the linking between the syncretic paradigmatic cells is to be represented. Hence, how does the system decide, which person the clitic takes? In Table 18, the syncretic template of Friulian regular verbs is presented. Strikingly, the syncretic forms are always grouped into the same pairs:

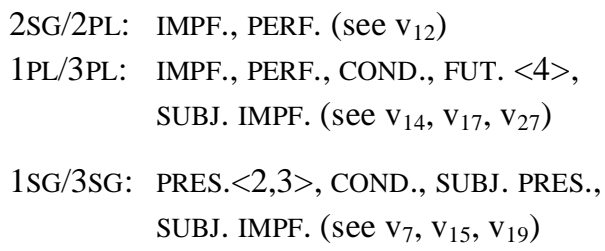


With respect to $2 \mathrm{SG}$ and $2 \mathrm{PL}$, I claim, that $2 \mathrm{SG}$ is chosen obligatorily instead of $2 \mathrm{PL}$, simply due to the fact, that the SCL has a consonantal onset which prevents two adjacent vowels to occur. ${ }^{23}$ Instead, the SCL of 2PL is purely vocalic and, moreover, syncretic, which means, that the choice favours the unambiguous 2SG SCL over the syncretic 2PL SCL. The preference of the $3 \mathrm{PL}$ over the 1PL clitic seems to follow the same logic. The 1PL $\mathrm{SCL}$ is deleted, in $* \mathrm{VV}]_{\mathrm{CG}^{-}}$contexts. Instead, the 3PL may be realized prenegatively. I assume, that the $3 \mathrm{PL}$ clitic is chosen over 1PL, since it is less syncretic. Syncretism of the 3PL clitic is only oberservable for Ampezzo with 3F.SG. Instead, the 1PL SCL exhibit syncretism with 2PL and 1SG. Due to the same reason, the latter is neither chosen with respect to the $1 \mathrm{SG} / 3 \mathrm{M} . \mathrm{SG}$ syncretism. The 2SG SCL is never realized prenegatively, since a violation of $* \mathrm{VV}]_{\mathrm{CG}}$ does not occur $(n o t u)$. The $3 \mathrm{M} . \mathrm{SG}$ SCL is neither realized in prenegative position, which is due to its consonantal coda.

The faithfulness constraint, that I call Linearity-IO, prevents SCLS from being realized in a position not directly adjacent to the verb. Obviously, this constraint is violated by the 3PL SCL. Nonetheless, it has to be stated, since other SCLS are not realized in prenegative position but are deleted in the context of negation: ${ }^{24}$ remember that preverbal SCLs occur in declarative sentences. In interrogative sentences the SCL is postponed to the verb. Hence, Linearity-IO further prevents the production of Verb-SCL sequences if they are not underlyingly present (i.e. in the input) in the linear order, in which they surface. With respect to interrogative sentences, I assume a

23 Moreover, marking may play an important role with respect to $2 \mathrm{SG}$. According to Greenberg (1966: 44-45), 2sG is the pronoun, which is marked the most. Therefore, its preference in the analyzed system and in NIDs (cf. Renzi \& Vanelli 1983 and Heap 2000, 2002) is far from being surprising.

24 As mentioned before, for Clauzetto, Brovedani (1981) observes prenegative SCLS with respect to 3SG. This does not contradict our results, since the SCL $a$ (3F.SG) is also syncretic. I assume that prenegative realization of $3 \mathrm{M} . \mathrm{SG}$ and 3F.PL occurs in analogy to $3 \mathrm{M} . \mathrm{PL}$ and 3F.SG although the former are not purely vocalic. 
correspondent lexical representation, where the SCL is already in postverbal position, e.g. /kjantavin a/.

The lowest ranked constraint is $\operatorname{Max}(\mathrm{SCL})$. This constraint requires the realization of SCLs; but obviously it might be violated even in default contexts.

The analysis can be summarized as follows:

As mentioned above, I assume that $* \mathrm{VV}]_{\mathrm{CG}}$ is the highest ranked constraint within the system. As exemplified in Table 16, for /no a kjantavin/, the optimal output is [a no kjantavin], although this violates Linearity-IO because of preverbal SCL realization, since all other candidates are ruled out due to their fatal violation of the first three constraints.

The OT-analysis presented here tries to deal with cases, where SCLs in a blocking environment are not realized. But the data in the previous sections clearly shows, that the individual speaker may prefer SCL realization even in such contexts where two adjacent vowels may occur within the CG. The advantage of OT is, that it can perfectly account to the individual grammar of the speakers. Hence, in this case, an adeguate analysis can be provided by means of a constraint re-ranking. E.g., with respect to jo o feveli (1), $\operatorname{Max}(\mathrm{SCL})$ is the highest ranked constraint in the grammar of an individual speaker, while $* \mathrm{VV}]_{\mathrm{CG}}$ is ranked lower. In the case of deleting the SCL in 3PL instead of realizing it prenegatively, $\operatorname{Max}(\mathrm{SCL})$ dominates $\operatorname{Max}\left(\mathrm{SCL}_{\mathrm{SCL} 2 \mathrm{SG}, 3 \mathrm{M} . \mathrm{SG}, 3 \mathrm{PL}}\right)$, if syncretism avoidance does not play any role to the speaker in this context. For Ligurian, Ciarlo (forthcoming) claims a structure a double Person projection - a higher ParticipantP with respect to first and second person, and a lower NonparticipantP (third person) above negation:

$$
\text { [PartP (SCL) [NonpartP (SCL) [NegP Neg... [TP]]]] }
$$

The syncretism is disambiguated realizing the nonparticipant directly above negation while the higher Person projection (PartP) is not pronounced.

Generally, it is not unproblematic to assume syncretism as a constraint for a given linguistic system. Baerman et al. (2005) show that syncretism is widespread in the languages of the world, and that there is little evidence bearing on strategies 
to avoid it. But Baerman (2009) also argues in favour of the existence of homophony avoidance strategies, e.g. with respect to some Berber languages and dialects such as Tamashek and Adrar, and regarding Icelandic, Russian, Tuvaluan and Mazatec. I follow Baerman's idea that some languages avoid syncretism, but others do not. An apparent extreme case is Icelandic, where syncretism is both tolerated and avoided in the same single paradigm (cf. Baerman 2009). From my point of view, this can even be attested for Italian, which presents syncretic forms in the $1 \mathrm{SG} / 2 \mathrm{SG} / 3 \mathrm{SG}$ present subjunctive. Italian is a prototypical null subject language (or pro-drop language), where an overt subject is not realized obligatorily, but only for contrast, focus, emphasis, anaphoric reference, etc. (cf. Rizzi 1986, Cordin \& Calabrese 2001). Nonetheless, according to Cordin \& Calabrese (2001), the present subjunctive forms are disambiguated by realizing the subject pronoun of $2 \mathrm{SG}$ in contrast to $1 \mathrm{SG}$ and $3 \mathrm{SG}$. At the same time, the latter syncretism is tolerated. Moreover, the imperfect subjunctive syncretism affecting $1 \mathrm{SG}$ and $2 \mathrm{SG}$ is again disambiguated by the use of the 2SG pronoun.

$$
\begin{array}{ll}
\text { PRES.SUBJ: } & \emptyset \text { possa }(1 \mathrm{SG}) / \text { tu possa }(2 \mathrm{SG}) / \\
& \emptyset_{\text {possa }}(3 \mathrm{SG}) \\
\text { IMPF.SUBJ: } & \emptyset \text { potessi }(1 \mathrm{SG}) / \text { tu potessi }(2 \mathrm{SG})
\end{array}
$$

Hence, syncretism avoidance plays a role in Romance languages. It is marginal with respect to Italian, but for Friulian I have shown that it plays an important role in the verb system.

\section{Summary}

The aim of this paper was to provide an analysis of SCL omission in Friulian. Omission occurs in the context of negation, and with OCLs and reflexive pronouns. A fieldwork study was carried out with 52 speakers from the three main varieties of Friulian, to consider also the diatopic aspects of variation.

Empirically, it has been shown that the grammaticality judgement data gathered corroborate the dominance of Block A over Block B as defined by Heap $(2000,2002)$ on the basis of Renzi \& Vanelli (1983). 
With respect to Friulian, those SCLs which significantly undergo deletion are purely vocalic and syncretic.

Syncretism does not only occur within SCLs but also within verb paradigms. The combinatorial approach shows that SCLs disambiguate syncretism. Against this backdrop I have shown that SCL deletion is not a paradox, since a syncretism avoiding constraint is responsible for prenegative SCL realization found for 3PL.

\section{References}

a) Primary source

Bibie = Battisti A., Vitale Bommarco A. \& Corrà S. (eds) (1999). La Bibie. Udin : Istitût Pio Paschini pe Storie de Glesie in Friûl.

b) Secondary sources

Ascoli G. I. (1873). «Saggi ladini », Archivio Glottologico Italiano I.

Baerman M. (2009). «Defectiveness and homophony avoidance », Journal of Linguistics, 1-29.

Baerman M., Brown D. \& Corbett G. (2005). The syntaxmorphology interface. Cambridge : Cambridge University Press.

Benincà P. (2005). «Lineamenti di grammatica friulana », in P. Benincà \& L. Vanelli (eds), Linguistica friulana. Padova : Unipress, 31-76.

Brandi L. \& Cordin P. (1989). "Two Italian dialects and the null subject parameter», in O. Jaeggli \& K. Safir (eds), The null subject parameter. Dordrecht : Kluwer, 111-142.

Brovedani L. (1981). La formazione delle frasi interrogative $e$ relative nella varietà friulana di Clauzetto, Tesi di laurea, Università degli studi di Padova.

Ciarlo C. (forthcoming). Subject clitic variation in a Northern Italian dialect, $\mathrm{PhD}$ thesis, Queen Mary University of London.

Cordin P. \& Calabrese A. (2001). «I pronomi personali », in L. Renzi, G. Salvi, \& A. Cardinaletti (eds), Grande 
grammatica italiana di consultazione I. Bologna: Il Mulino, 549-606.

Crosswhite K. (2001). Vowel reduction in optimality theory. New York, London : Routledge.

Elwert W. T. (1943). Die Mundart des Fassa-Tals. Wiesbaden.

Francescato G. (1966a). Studi linguistici sul friulano. Firenze : Olschki.

Francescato G. (1966b). Dialettologia friulana. Udine : Società filologica friulana.

Frau G. (1984). Friuli. Pisa : Pacini.

Gartner T. (1883). Raetoromanische Grammatik. Heilbronn : Henninger.

Greenberg J. H. (2005 [1966]). Language universals: with special reference to feature hierarchies (with a preface by Martin Haspelmath). Berlin, New York: Mouton de Gruyter.

Gregor D. B. (1975). Friulan: language and literature. New York, Cambridge : Oleander Press.

Hack F. M. \& Gaglia S. (2009). « The use of subject pronouns in Raeto-Romance: a contrastive study », in G. Kaiser \& E. M. Remberger (eds), Null-subjects, expletives and locatives in Romance, Arbeitspapier Nr. 123, Fachbereich Sprachwissenschaft, Universität Konstanz, 157-181. (http://ling.uni-konstanz.de/pages/publ/arbeitspapiere.html)

Haiman J. (1991). «From V/2 to Subject Clitics: Evidence from Northern Italian », in E. Traugott \& B. Heine (eds), Approaches to grammaticalization. Vol. II: Focus on types of grammatical markers. Amsterdam \& Philadelphia: Benjamins, 135-157.

Haiman J. \& Benincà P. (1992). The Rhaeto-Romance languages. London : Routledge.

Heap D. (2000). La variation grammaticale en géolinguistique: les pronoms sujet en roman central. Munich : Lincom.

Heap D. (2002). «Split subject pronoun paradigms: feature geometry and underspecification », in T. Satterfield, 
C. Tortora \& D. Cresti (eds), Current issues in Romance languages: selected papers from the 29th Linguistic Symposium on Romance Languages (LSRL). Amsterdam, Philadelphia : Benjamins, 129-144.

Heinemann S. (2003). Studien zur Stellung des Friaulischen in der nördlichen Italoromania. Bonn : Romanistischer Verlag.

Kaiser G. A., Carigiet W. \& Evans M. (2001). "RaetoRomance », in T. Stolz (ed), Minor languages of Europe. A series of lectures at the University of Bremen. Bochum : Universitätsverlag, 183-210.

Liver R. (2010). Rätoromanisch: eine Einführung in das Bündnerromanische, 2, überarbeitete Auflage. Tübingen : Narr.

Manzini M. R. \& Savoia L. (2005). I dialetti italiani e romanci. Morfosintassi generativa vol. I. Alessandria: Edizioni dell'Orso.

Marchetti G. (1952). Lineamenti di grammatica friulana, Terza edizione. Udine : Società Filologica Friulana.

McCarthy J. \& Prince A. (1993). «Generalized alignment», in G. Booij \& J. van Marle (eds), Yearbook of Morphology 1993. Dordrecht : Kluwer, 79-153.

Nespor M. \& Vogel I. (2007). Prosodic Phonology: with a new foreword. Berlin, New York : De Gruyter.

Poletto C. (2000). The higher functional field: evidence from Northern Italian dialects. Oxford: Oxford University Press.

Prince A. \& Smolensky P. (1993). Optimality Theory: Constraint Interaction in Generative Grammar. Technical Report 2, Rutgers University Center for Cognitive Science.

Renzi L. \& Vanelli L. (1983). «I pronomi soggetto in alcune varietà romanze », in P. Benincà, M. Cortelazzo, A. L. Prosdocimi, L. Vanelli \& A. Zamboni (eds), Scritti linguistici in onore di G. B. Pellegrini. Padova: Pacini, 121-145. 


\section{S. GAGLIA}

Rizzi L. (1986). « On the status of subject clitics in Romance », in O. Jaeggli \& C. Silva-Corvalan (eds), Studies in Romance linguistics. Dordrecht : Foris, 391-419.

Spencer A. (1991). Morphological Theory. Oxford : Blackwell.

Trask R. L. (1997). A student's dictionary of language and linguistics. London : Arnold.

Vanelli L. (1997). «Friuli », in M. Maiden \& M. Parry (eds), The dialects of Italy. London : Routledge, 279-285.

Vanelli L. (1998). I dialetti italiani settentrionali nel panorama romanzo : Studi di sintassi e morfologia. Roma : Bulzoni.

Vanelli L. (2005). «La posizione del friulano nel dominio romanzo », in P. Benincà \& L. Vanelli (eds), Linguistica friulana. Padova : Unipress, 19-30.

Vicario F. (2005). Lezioni di linguistica friulana. Udine : Forum. 